\title{
Evaluation of Dynamic Postural Balance in Pediatric Familial Mediterranean Fever Patients
}

\author{
'Selçuk University Faculty of Medicine, Department of Pediatrics, Konya, Turkey \\ ${ }^{2}$ Academic Pain and Heritage Center, Clinic of Physical Therapy and Rehabilitation, Samsun, Turkey \\ ${ }^{3}$ Başkent University Faculty of Medicine, Department of Pediatrics, Ankara, Turkey \\ ${ }^{4}$ Oltu State Hospital, Clinic of Pediatrics, Erzurum, Turkey \\ ${ }^{5}$ Gaziosmanpaşa University Faculty of Medicine, Department of Pediatrics, Tokat, Turkey
}

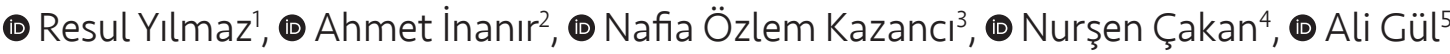

\begin{abstract}
Aim: Familial Mediterranean Fever (FMF) is an autoinflammatory and chronic disorder. Colchicine has been prescribed to treat FMF since 1972. Balance is a complex function of the neuromuscular system. The aim of this study is to determine 1 ) if there is a connection between FMF and dynamic balance, 2) if colchicine use affects balance, and 3) if the disease severity score is related to a disruption in balance.

Materials and Methods: The study examined 50 pediatric patients with FMF and 130 healthy age- and sex-matched children as control subjects. Dynamic postural stability was measured using the Biodex Stability System (BSS).

Results: The stability indices were significantly higher in the FMF group than in the controls. There was no relationship between the FMF disease severity score and the three stability indices, while the colchicine dose was related to all three stability indices.

Conclusion: By detecting any change in balance status early using a simple, safe, objective measurement of balance via the BSS in FMF patients, neuromyopathy could be identified earlier and unwanted outcomes prevented.

Keywords: Dynamic balance, Biodex Stability System, colchicine, Familial Mediterranean Fever, children
\end{abstract}

\section{Introduction}

Familial Mediterranean Fever (FMF) is an autoinflammatory disorder with autosomal recessive inheritance that is characterized by recurrent episodes of fever, arthritis, and serosal inflammation (1,2). Although its attacks are selflimited, AA type amyloidosis is the most prominent and lifethreatening consequence of FMF. FMF is common in Turks, Jews, Arabs, Armenians and other Mediterranean basin and Middle East populations (3).

Balance is a complex function of the neuromuscular system $(4,5)$. It is controlled by sensory input, central processing and neuromuscular responses. Vestibular, proprioceptive and visual inputs are the major sensory inputs (6). Controlling static and dynamic balance is essential for daily living and participating in physical exercise and sports (7). Although healthy subjects can maintain a stable posture and balance automatically, it can be challenging if the sensory inputs are disrupted or brain functions are damaged $(8,9)$. The Biodex Stability System (BSS) is reliable for evaluating dynamic postural balance in healthy (10-12) and blind (13) individuals and has been used to evaluate postural balance in recent years $(10-12,14)$. Pain processing can cause balance disorders (15). A possible explanation for this is that in central nervous system pain processing, the balance control circuit and paininduced inhibition of muscles share the same pathways and 
pain has a negative influence on proprioceptive feedback from painful structures $(8,9)$. Colchicine has been prescribed to treat FMF since 1972. It reduces the frequency of attacks and prevents the development of amyloidosis $(16,17)$. Colchicine is also used to treat gout and Behçet's disease. Its most common and reversible side effects are nausea, abdominal cramps and diarrhea $(18,19)$. High doses of colchicine can cause severe side effects, such as disseminated intravascular coagulation, bone marrow suppression and renal damage (20). However, toxicity is also observed with standard doses (21). Neuromyopathy related to colchicine presents as distal areflexia, mild sensory changes and weakness of the proximal muscles and increased creatine kinase levels and low motor unit potentials on electromyography. To our knowledge, no study has investigated the influence of FMF on the balance system. Therefore, this study aims to see 1) if there is a connection between FMF and dynamic balance, 2) if colchicine use affects balance, and 3 ) if the disease severity score is related to a disruption in balance.

\section{Materials and Methods}

The study examined 50 child patients with FMF (19 males, 31 females) and 130 healthy age- and sex-matched (65 males, 65 females) children as control subjects. All subjects were recruited from the Gaziosmanpaşa Health Research and Practice Center, Pediatric outpatient clinics between June and September 2013. The study was approved by the Gaziosmanpaşa University Clinical Research Ethics Committee (approval number: 12-BADK-046). All procedures were conducted after written informed consent was obtained from patients or guardians. The diagnosis of FMF was established using the Tel-Hashomer criteria (22). All patients were in remission and on colchicine treatment. None of the patients or controls were taking any drugs that could affect balance, other than colchicine for those in the patient group. Individuals who had psychiatric, neurological or orthopedic problems, muscle disease, limited mobility, motor deficits, inflammatory arthritis, previous spinal surgery, vertigo, diabetes, or visual or auditory problems were excluded from the study. The oral dose of colchicine is $0.5,1$ or $1.5 \mathrm{mg}$ per day in children $<5,5-10$, or $>10$ years old, respectively (23). A recent study in Turkey proposed that children with FMF should be prescribed colchicine according to body weight and surface area; however, the mean colchicine dose was calculated to exceed the age-based dosage (24). The FMF disease severity scores were calculated based on the age at disease onset, number of attacks per month, amyloidosis status, arthritis status, colchicine dose and the presence or absence of erysipelas-like erythema at the time of admission. Scores of $3-5,6-8$, and $\geq 9$ were considered to reflect mild, moderate and severe disease respectively (25). Demographic data and information on disease duration and current colchicine dose were retrieved from our hospital database or collected during patient interviews. Dynamic postural stability was measured using the BSS. There is a movable balance platform that provides up to $20^{\circ}$ of surface tilt in a $360^{\circ}$ range of motion. The platform was combined with computer software (3.1 Biodex), which allows the device to serve as an objective assessment of balance. The measure of postural stability includes the overall (OASI), anterior-posterior (APSI) and medial-lateral (MLSI) stability index scores. The scores range between $0^{\circ}$ and $20^{\circ}$ for all stability indexes. Poor balance is identified with a high stability index score (26). A dynamic postural balance score was obtained from measurements of the BSS at level 8 . The difficulty levels of the system range from 1 (most difficult) to 8 (easiest). It was decided to set the platform at level 8 because this meant that it could be used in all subjects, allowing testing of all patients at the same level. Results were calculated as the mean of three measurements made at 20-second intervals. The BSS parameters were compared between the FMF patients and control group. All data were analyzed using the Statistical Package for the Social Sciences ver. 18.0 (SPSS, Chicago, IL, USA). Analysis of variance was performed using Dunnett's post hoc test to analyze between-group differences. Differences between FMF patients and the control group were assessed using the Mann-Whitney $U$ test when the parameters were not normally distributed and the Student's t-test for normally distributed continuous variables. $\mathrm{P}<0.05$ was considered significant.

\section{Results}

The demographic and clinical features of the FMF patients and matched controls are summarized in Table I. There were no significant differences between the groups with regard to age, sex and body mass index (BMI). The dynamic postural balance results for the groups are also shown in Table I. The results were based on the average of the three tests. The OASI, APSI and MLSI were significantly higher in the FMF group than in the controls. There was no relationship between the FMF disease severity score and the three stability indices, while the colchicine dose was related to all three stability indices (Table II).

\section{Discussion}

This study demonstrated that FMF can influence postural balance. In addition, we found a relationship between the stability indices and the colchicine (the main treatment for FMF) dose, but no correlation between the stability indices and arthritis or the FMF disease severity score. Achieving proper postural balance is a complex process. Visual, vestibular and proprioceptive sensory inputs need to be integrated centrally. Visual and peripheral sensory inputs and muscle strength 


\begin{tabular}{|c|c|c|c|c|c|}
\hline & \multicolumn{2}{|c|}{ Familial Mediterranean Fever patients } & \multicolumn{2}{|c|}{ Healthy controls } & $\mathrm{p}$ value \\
\hline \multirow[t]{2}{*}{ Sex } & \multicolumn{2}{|c|}{31 girls (52\%) } & \multicolumn{2}{|c|}{65 girls $(54.2 \%)$} & 0.348 \\
\hline & Mean & Standard deviation & Mean & Standard deviation & \\
\hline Age & 11.31 & 2.82 & 10.66 & 1.78 & 0.140 \\
\hline Body mass index & 17.88 & 3.85 & 18.66 & 3.46 & 0.311 \\
\hline Overall stability index & 1.14 & 0.77 & 0.85 & 0.52 & 0.025 \\
\hline Anteroposterior stability index & 0.79 & 0.47 & 0.59 & 0.38 & 0.039 \\
\hline Mediolateral stability index & 0.68 & 0.47 & 0.51 & 0.35 & 0.034 \\
\hline
\end{tabular}

Table II. Correlation analysis of Familial Mediterranean Fever patients (" $r$ " values)

\begin{tabular}{|l|l|l|l|}
\hline & \multicolumn{3}{l|}{ Stability indices } \\
\hline & Overall & Anteroposterior & Mediolateral \\
\hline Colchicine dose & $-\mathbf{0 . 4 0 0 *}$ & $-\mathbf{0 . 3 8 8 ^ { * }}$ & $-\mathbf{0 . 4 3 9 *}$ \\
\hline Disease severity score & 0.064 & 0.030 & 0.093 \\
\hline$* 0<01$ & &
\end{tabular}

are important determinants of balance (5,27-30). Treede et al. (15) and Hassan et al. (8) explained balance disorder as a function of common or close pathways of pain processing, the balance control system and pain-induced muscle inhibition (27). FMF is a chronic disease characterized by abdominal pain, arthritis, chest pain and synovitis. Based on the discussion above, pain processing might lead to decreased balance control in FMF patients, and several potential mechanisms might be responsible for the balance impairment observed in FMF patients. Pain associated with synovitis in FMF patients might be related to balance impairment, although all of our patients were free from attacks during the study and had no pain. Therefore, pain played no role in balance impairment in our patient group. Higher FMF disease severity scores reflect severe disease activity (25). We hypothesized that higher severity scores were related to impaired balance, but there was no relationship between the FMF disease severity scores and the stability indices in our study. Aydoğ et al. (31) and Ekdahl et al. (32) evaluated the impact of disease activity on balance control in rheumatoid arthritis (RA) patients. While Aydoğ et al. (31) found no relationship for balance with disease duration, the inflammatory marker Disease Activity Score 28 or C-reactive protein (CRP) levels, Ekdahl et al. (32) determined that CRP levels affected balance control (5). The Health Assessment Questionnaire (HAQ), which has been used widely to evaluate disability in daily activities, can reflect the severity of disease (33). Luoto et al. (34) and Aydoğ et al. (31) found a significant association between high HAQ scores and a poor performance on the balance test in RA patients. Aydoğ et al. (31) concluded that balance was affected by functional status rather than RA disease activity. In our study, we did not detect inflammatory activity, measure the CRP or assess HAQ scores and thus cannot compare these parameters in our patients. Neuromuscular complications associated with colchicine use are one of the less recognized causes of neuromyopathy (35). Colchicinedependent neuromyopathy is reversible, in that the laboratory and clinical abnormalities resolve after colchicine withdrawal (20). Given the availability of colchicine over the counter and its wide use in FMF patients, neuromyopathy might be more common than expected. In our study, there was a positive correlation between colchicine doses and stability indices.

\section{Study Limitations}

Our study is not without limitations. We measured balance during attack-free periods, and thus could not compare balance between attack and attack-free periods and assess the effects of pain. The second limitation was the lack of an evaluation of the effects of vestibular, visual and proprioceptive sensory inputs. Future, prospective studies on the effects of these sensory inputs on balance might provide more accurate results in FMF patients. A third limitation of the study was its cross-sectional design, which prevented us from determining a cause-effect relationship. Another limitation was the disease severity index used in our study is no longer up to date. The new activity index known as the Autoinflammatory Disease Activity index should be used in the future in prospective studies.

\section{Conclusion}

Due to the complex control of balance, impairment of any control component, such as sensory inputs, central processing or neuromuscular responses, could cause a balance disorder. Peritonitis, pleuritis and arthritis, which cause pain in FMF, could affect the central center of balance. The main medication used in FMF patients, colchicine, can cause neuromyopathy and may lead to balance disorders. By 
detecting any change in balance status early using a simple, safe, objective measurement of balance with the BSS in FMF patients, neuromyopathy could be identified earlier and unwanted outcomes prevented.

\section{Ethics}

Ethics Committee Approval: The study was approved by the Gaziosmanpaşa University Clinical Research Ethics Committee (approval number: 12-BADK-046).

Informed Consent: All procedures were conducted after written informed consent was obtained from patients or guardians.

Peer-review: Externally peer-reviewed.

\section{Authorship Contributions}

Medical Practices: R.Y., A.I., N.Ö.K., N.Ç., Concept: R.Y., A.I.., N.Ö.K., N.Ç., Design:R.Y., A.I., Data Collection orProcessing:R.Y., A.I., N.Ö.K., N.Ç., A.G., Analysis or Interpretation: R.Y., A.I.,, N.Ö.K., N.Ç., A.G., Literature Search: R.Y., A.İ., N.Ö.K., N.Ç., A.G., Writing: R.Y.

Conflict of Interest: No conflict of interest was declared by the authors.

Financial Disclosure: The authors declared that this study received no financial support.

\section{References}

1. Yilmaz R, Ozer S, Ozyurt H, Erkorkmaz U, Sahin S. Familial Mediterranean fever gene mutations in the inner northern region of Turkey and genotype-phenotype correlation in children. J Paediatr Child Health 2009;45:641-5.

2. Saatçi U, Ozen S, Ozdemir S, et al. Familial Mediterranean fever in children: report of a large series and discussion of the risk and prognostic factors of amyloidosis. Eur I Pediatr 1997;156:619-23.

3. Eliakim M, Levy M, Ehrenfeld M. Recurrent Polyserositis: Familial Mediterranean Fever, Periodic Disease. Elsevier/North-Holland Biomedical Press Amsterdam, 1981.

4. Stelmach GE, Teasdale N, Di Fabio RP, Phillips ). Age related decline in postural control mechanisms. Int J Aging Hum Dev 1989;29:205-23.

5. Jones GE. Posture. In: Kandel E, Schwartz J, Jessel T (eds). Principles of neural science, Vol 4, McGraw-Hill, 2000. p.816-31.

6. Shumway-Cook A, Horak FB. Assessing the influence of sensory interaction of balance. Suggestion from the field. Phys Ther 1986;66:1548-50.

7. Ulrich $B$, Ulrich $D$. The role of balancing ability in performance of fundamental motor skills in 3-, 4-, 5-year-old children. In: Clark J, Humphrey I (eds). Motor development: Current selected research, Vol 1, Princeton, Princeton Book Co, 1985. p.87-97.

8. Hassan BS, Mockett S, Doherty M. Static postural sway, proprioception, and maximal voluntary quadriceps contraction in patients with knee osteoarthritis and normal control subjects. Ann Rheum Dis 2001;60:612-8.

9. Ruhe A, Fejer R, Walker B. Pain relief is associated with decreasing postural sway in patients with non-specific low back pain. BMC Musculoskelet Disord 2012;13:39.

10. Baldwin S, VanArnam T, Ploutz-Snyder L. Reliability of dynamic bilateral postural stability on the Biodex Stability System in older adults. Mid-Atlantic Chapter of the American College of Sports Medicine. 2004;36:30.

11. Schmitz RJ, Arnold BL. Intertester and intratester reliability of a dymanic balance protocol using Biodex Stability System. I Sport
Rehabil 1998;7:95-101.

12. Pincivero $D$, Lephart $S$, Henry T. Learning effects and reliability of the Biodex Stability System. I Athl Train 1995;30:S35.

13. Aydog ST, Aydog E, Cakci A, Doral MN. Reproducibility of postural stability scores in blind athletes. Isokinet Exerc Sci 2004;12:229-32.

14. Testerman C, Vander Griend R. Evaluation of ankle instability using the Biodex Stability System. Foot Ankle Int 1999;20:317-21.

15. Treede RD, Apkarian AV, Bromm B, Greenspan JD, Lenz FA. Cortical representation of pain: functional characterization of nociceptive areas near the lateral sulcus. Pain 2000;87:113-9.

16. Ben-Chetrit E, Levy M. Familial Mediterranean fever. Lancet 1998;351:659-64.

17. Goldfinger SE. Colchicine for familial Mediterranean fever. N Engl I Med 1972;287:1302

18. Zemer D, Pras M, Sohar E, Modan M, Cabili S, Gafni J. Colchicine in the prevention and treatment of the amyloidosis of familial Mediterranean fever. N Engl / Med 1986;314:1001-5.

19. Miyachi Y, Taniguchi S, Ozaki M, Horio T. Colchicine in the treatment of the cutaneous manifestations of Behçet's disease. Br J Dermatol 1981;104:67-9.

20. Kuncl RW, George EB. Toxic Neuropathies and Myopathies. Curr Opin Neurol 1993;6:695-704.

21. Wallace SL, Singer IZ, Duncan G), Wigley FM, Kuncl RW. Renal function predicts colchicine toxicity: guidelines for the prophylactic use of colchicine in gout. I Rheumatol 1991;18:264-9.

22. Livneh A, Langevitz $P$, Zemer $D$, et al. Criteria for the diagnosis of familial Mediterranean fever. Arthritis Rheum 1997;40:1879-85.

23. Majeed HA, Rawashdeh M, el-Shanti H, Qubain H, Khuri-Bulos $\mathrm{N}$, Shahin HM. Familial Mediterranean fever in children: the expanded clinical profile. QJM 1999;92:309-18.

24. Ozkaya N, Yalcinkaya F. Colchicine treatment in children with familial Mediterranean fever. Clin Rheumatol 2003;22:314-7.

25. Pras E, Livneh A, Balow JE Jr, et al. Clinical differences between North African and Iraqi Jews with familial Mediterranean fever. Am J Med Genet 1998;75:216-9.

26. Testerman C, Vander Griend R. Evaluation of ankle instability using the Biodex Stability System. Foot Ankle Int 1999;20:317-21.

27. Horak FB, Shupert CL, Mirka A. Components of postural dyscontrol in the elderly: a review. Neurobiol Aging 1989;10:727-38.

28. Woollacott MH, Shumway-Cook A, Nashner LM. Aging and posture control: changes in sensory organization and muscular coordination. Int ) Aging Hum Dev 1986;23:97-114.

29. Kollegger $H$, Baumgartner C, Wöber C, Oder W, Deecke L. Spontaneous body sway as a function of sex, age, and vision: posturographic study in 30 healthy adults. Eur Neurol 1992;32:253-9.

30. Ring C, Nayak US, Isaacs B. The effect of visual deprivation and proprioceptive change on postural sway in healthy adults. I Am Geriatr Soc 1989;37:745-9.

31. Aydoğ E, Bal A, Aydoğ ST, Cakci A. Evaluation of dynamic postural balance using the Biodex Stability System in rheumatoid arthritis patients. Clin Rheumatol 2006;25:462-7.

32. Ekdahl C. Postural control, muscle function and psychological factors in rheumatoid arthritis. Are there any relations? Scand ) Rheumatol 1992;21:297-301.

33. Kirwan IR, Reeback JS. Stanford Health Assessment Questionnaire modified to assess disability in British patients with rheumatoid arthritis. Br I Rheumatol 1986;25:206-9.

34. Luoto S, Riikonen K, Siivola M, Laiho K, Kauppi M, Mikkelsson M. Impaired postural control is associated with worse scores of the Health Assessment Questionnaire disability index among women with rheumatoid arthritis. I Rehabil Med 2011;43:900-5.

35. Altiparmak MR, Pamuk ON, Pamuk GE, Hamuryudan V, Ataman $\mathrm{R}$, Serdengecti K. Colchicine neuromyopathy: a report of six cases. Clin Exp Rheumatol 2002;20(4 Suppl 26):13-6. 